\title{
Drought in Ethiopia: A Population Health Equity Approach to Build Resilience for the Agro-Pastoralist Community
}

\author{
Selim M. Khan ${ }^{1} \&$ James Gomes ${ }^{2}$ \\ ${ }^{1}$ Interdisciplinary Population Health, Faculty of Health Sciences, University of Ottawa, 25 University Private, \\ Ottawa, Canada \\ ${ }^{2}$ Faculty of Health Sciences, University of Ottawa, 25 University Private, Ottawa, Canada \\ Correspondence: Selim Khan, Interdisciplinary Population Health, Faculty of Health Sciences, University of \\ Ottawa, 25 University Private, Ottawa, K1N 7K4, ON, Canada. E-mail: skhan196@uottawa.ca
}

Systematic Review \# CRD42018116904; Registered with the National Institute for Health Research.

Received: October 7, 2018 Accepted: January 6, 2019 Online Published: January 10, 2019

doi:10.5539/gjhs.v11n2p42 URL: https://doi.org/10.5539/gjhs.v11n2p42

\begin{abstract}
Background: A devastating drought is ravaging Africa, with Ethiopia being the worst-hit country. Ethiopia's economy is predominantly reliant on rain-fed farming and livestock. The agriculture sector contributes up to $85 \%$ of the country's livelihoods. The drought has threatened agro-economy and health of over 15 million agro-pastoralist population who herd the largest livestock in Africa. Some governments announced its commitment in the UN to extend support for the drought-affected people. The Sendai framework for Disaster Risk Reduction prioritizes proactive rather than reactive relief response that can promote health resilience. Applying population health matrices can serve the purpose by exploring the determinants of health, their impacts on the differential health outcomes for population sub-groups and to improve the overall health of the population by addressing the health inequity.
\end{abstract}

Objective: This study aims to identify the critical population health outcomes, underlying determinants, and the leverage points for actions that can guide effective policies and interventions for building health resilience for the vulnerable agro-pastoralist population in Ethiopia.

Methods: Two researchers searched nine academic and grey literature bibliographic databases for drought literature and related health interventions. We used the PRISMA checklist to synthesize data and Hamilton tools to evaluate individual study quality. We analyzed data employing disaster vulnerability and WHO's social determinants of health and health equity frameworks. Socioeconomic, political and cultural backgrounds are examined to identify policy and leverage points for effective population health interventions.

Results: Health issues are diverse that revolve around the major determinants of health such as food security, infrastructure, health systems, disaster preparedness, household productivity-income, livestock dependence and access to the market economy. These determinants are further affected by socioeconomic, political and cultural contexts. Despite dire vulnerability and health inequity, some potentials evolved from recent public health field practices as the leverage points for policy actions and interventions.

Conclusion: The recommended interventions can be implemented through an interdisciplinary population health approach to get the maximum impacts on health resilience. Evidence gathered from the worst drought niche in Africa can be useful to tackle similar droughts induced health issues in other parts of the continent. Future intervention research on the ground can generate robust evidence for action to build health resilience.

Keywords: Drought, heath, determinants, vulnerability, resilience, inequity, policy, intervention.

Drought in Ethiopia: Canadian Support to Build Health Resilience for the Agro-Pastoralist Community

\section{Introduction}

A widespread drought is currently ravaging several East African countries (UNOCHA, 2017). However, the focus of this review is Ethiopia, where the devastation is greater than anywhere else (Birhanu et al., 2017). Since the mid-1950s, the country has been hit by 12 major drought-induced food security crises (Tadesse et al., 2016). 
Communities affected by drought face physical, mental, and socioeconomic stress (Nomura et al., 2016). A water shortage results in crop failure, loss of livestock, and food scarcity. The ensuing famine imparts immediate and long-term implications for the health of the population, the viability of the health systems, and the health-sustaining socioeconomic conditions. Some vulnerable subpopulations suffer disproportionately from the health consequences of drought (Tadesse et al., 2014).

A paradigm shift was made during the 2015 United Nations World Conference held in Japan by adopting the 'Sendai Framework for Disaster Risk Reduction 2015-30' that called for a proactive rather than reactive disaster response and prioritized health resilience (UNDRR, 2015). Similarly, the World Health Organization's Commission on Social Determinants of Health (CSDH) framework calls for addressing the vulnerability and health inequity through improving health-supporting systems and determinants (WHO, 2010). The Government of Ethiopia $(\mathrm{GoE})$ is committed to reducing the disaster toll through preparedness, risk reduction, and capacity building (GoE, 2013). Accordingly, a National Disaster Risk Management Commission (NDRMC) is tasked with coordinating activities across government sectors and beyond (UNHP, 2016). Currently, the Ministry of Health $(\mathrm{MoH})$ is leading the intersectoral teams to remediate health and nutrition problems caused by the drought. Thus, this is a collaboration effort between the health, education, and agriculture sectors to serve the policy objectives. However, there is a lack of resources as well as evidence-based policy and programs to accomplish these goals.

The governments from many countries expressed commitment to support the UN efforts to tackle this crisis through financial and technical support. This study reviewed evidence using the population health frameworks to identify the determinants of health that can guide relief efforts by the host government to develop health resilience for their most vulnerable population. Therefore, we addressed the following research questions:

1. What are the implications of a drought on the health of the vulnerable Ethiopian agro-pastoralist population?

2. How are the social and structural determinants contributing to their health inequity?

3. What are the existing coping mechanisms to build on the leverage points for actions?

4. What socio-political issues dictate health policy and intervention decisions to ensure health resilience for the target population?

\section{Materials and Methods}

Two researchers searched separately searched PubMed (MEDLINE), Embase, PsycINFO, Scopus, CINAHL (EBSCO), Web of Science, JSTOR, and Global Health database from July 1 to 7, 2017. Search words included: drought, Africa, Ethiopia, health, population, agro-pastoralist, vulnerability, prevention, risk reduction, food security, livelihood, livestock, resilience building, intervention, research, cost-effectiveness, and sustainability. We identified 473 database records. We searched Google Scholar from July 8 to 15,2017 , using the same key terms and identified 91 hits. Thus, both authors identified a total of 564 documents. 351 database records remained after removing the duplicates. 134 documents sustained initial relevance screening. We found only 76 full-text articles, of which 47 met eligible criteria. After full-text skimming, we retain 27 articles and eliminate 20 articles for not meeting one or more criteria and for being out of context of our review. After reading full-texts, we finally selected 18 peer-reviewed articles for this review as 9 articles were not considered of adequate quality. The websites of the Government of Ethiopia, key international and regional agencies, non-governmental organizations, and institutions were searched for information on relevant documents. Hand-searching the references of related articles identified more records from the libraries of the University of Ottawa. 


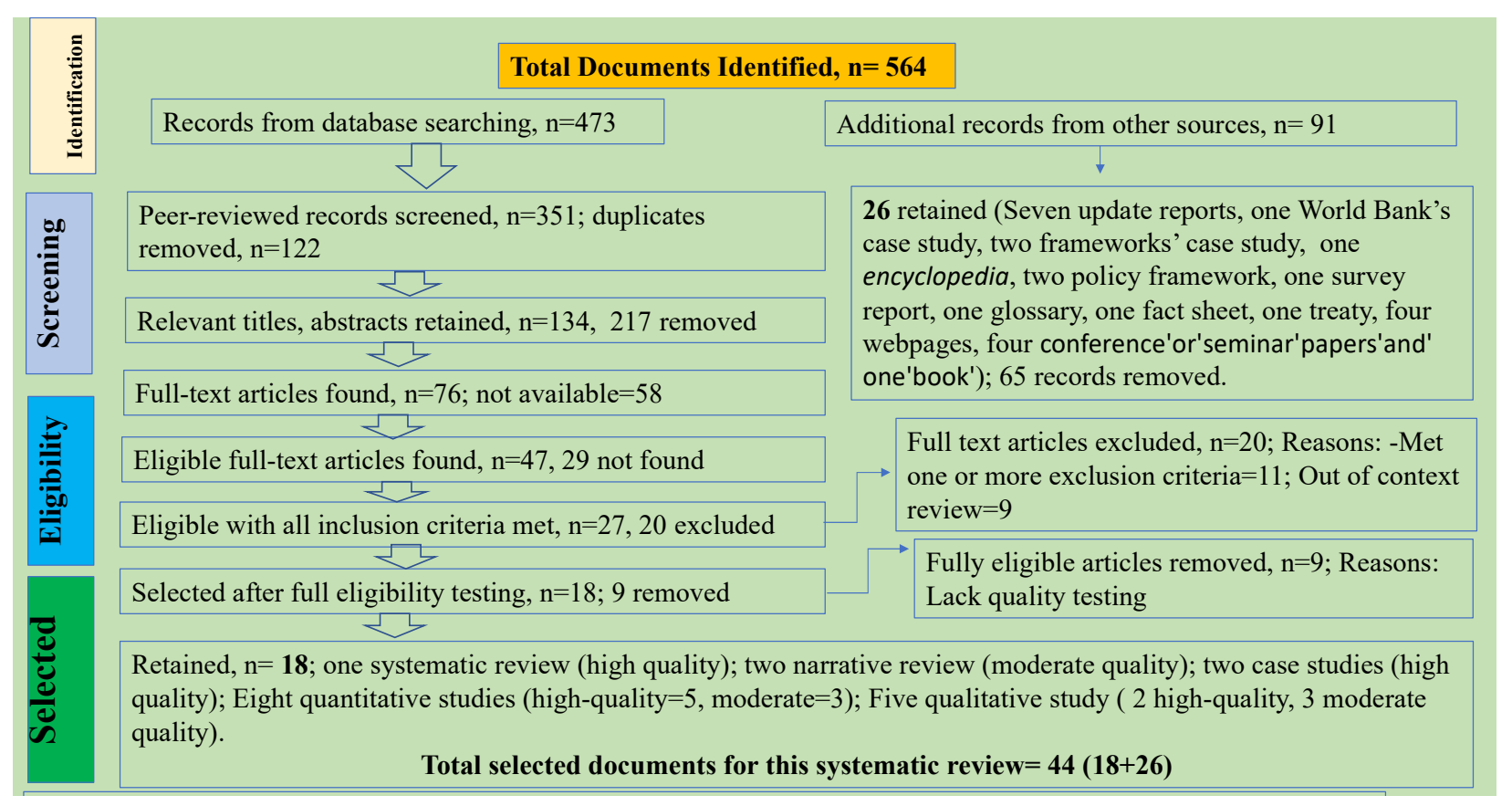

Figure 1. Presents the PRISMA flowchart for the literature search

\section{Search Results}

We included 44 documents for the final review. Among the 18 were peer-reviewed articles, one was a systematic review, two narrative reviews, five qualitative studies, two case studies and other 8 were quantitative studies. 26 were various types of documents. Among them, Seven reports, one World Bank's case study, two frameworks' case study, one encyclopedia, two policy framework reviews, one survey report, one glossary, one fact sheet, one treaty, four web pages, four conference or seminar papers and one book. As variations of measures made very little quantitative synthesis was possible that precluded any meta-analysis. The disparities remained even after grouping up the interventions and outcomes. As only a few studies reported data that were amenable to the calculation of standardized effect sizes, so performed a narrative review.

\subsection{Drought and Population Health Perspectives: The Conceptual Frameworks}

The Food and Agriculture Organization and National Drought Mitigation Center at the University of Nebraska-Lincoln jointly define drought as "a deficiency of precipitation over an extended period - usually a season or more - resulting in a water shortage for some activity, group, or environmental sector" (FAO \& NDMC, 2008). Regarding typology, droughts can be meteorological, agricultural, hydrological, and socio-economic. In all cases, there is not enough rainfall over an extended period, producing a severe hydrological imbalance for the sustenance of lives and livelihoods (NOA, 2002). Socioeconomic drought differs markedly from other types, as it is associated with the supply and demand for economic goods (UNISDR, 2009). These have a profound impact on the health determinants and health outcomes of the affected population.

According to Kindig and Stoddart (2003), population health consists of "the health outcomes of a group of individuals, including the distribution of such outcomes within the group" (p.381). They argue that the field of population health must emphasize the concept and measurement of health outcomes because these draw the research focus on the impact of the determinants of health and their interactions with one another. They also believe that this approach would help to elucidate the health inequality among population sub-groups. They maintain that these relate to underlying ethical considerations that drive policies and interventions to address the health determinants. Finally, they make clear the goals of population health, which are to maintain and improve the overall health of a population and reduce health inequities among population sub-groups (Kindig et al., 2003). In reviewing the literature and identifying population health implications and underlying determinants, we put these perspectives into focus. As such, we used the 'general health impact pathway' (Few, 2007) to identify health issues; employed the 'Ecosocial perspective' (Krieger, 2001) to assess drought vulnerability and engaged with the 'social determinants of health (WHO, 2010) frameworks' to determine leverage points for interventions. 


\section{Review Outcomes}

\subsection{Drought Devastating Ethiopian Agro-Economy}

Ethiopia's economy is predominantly reliant on low-input rain-fed farming and livestock (FAO, 2016). The agriculture sector contributes up to $45 \%$ of the country's GDP and $85 \%$ of livelihoods (EGP, 2016). The lack of successive rainy seasons since mid-2015 exerts crushing effects on the country's agro-economic system. The country's dependency on agriculture combined with its ongoing political fragility make the shock of drought harder to absorb (Birhanu et al., 2017). Over 15 million agro-pastoralists in Ethiopia are herding livestock in drought-prone arid and semi-arid areas (MoA, 2013). Despite making crucial contributions to the economy, these communities remain marginalized (Downie, 2016). Current drought conditions are affecting the lives and livelihoods of over 10.2 million people (UNOCHA, 2017). Among them, over 5.6 million people including 2.7 million children, pregnant and lactating women are currently facing a food crisis (UNOCHA, 2017).

\subsection{Drought Induced Population Health Outcomes in Ethiopia}

As a direct effect of the global climatic changes, there have been very few rainfalls in Ethiopia since 2015 (FAO, 2016; IPCC, 2014). The consecutive droughts have drastically reduced water resources, resulting in crop failures and a shortage of food (JGHP, 2017). The health impacts are complex and long lasting, with profound effects on life-sustaining resources, activities, mechanisms, and systems (Nomura et al., 2016). Although health effects are presented linearly, they are often mutually reinforcing and encompass multiple cycles with interrelated feedback loops that are too broad to show in any single framework. Few's (2007) general health impact pathway of climatic impacts (Figure 2) is shown here to illustrate the population health impacts of drought.

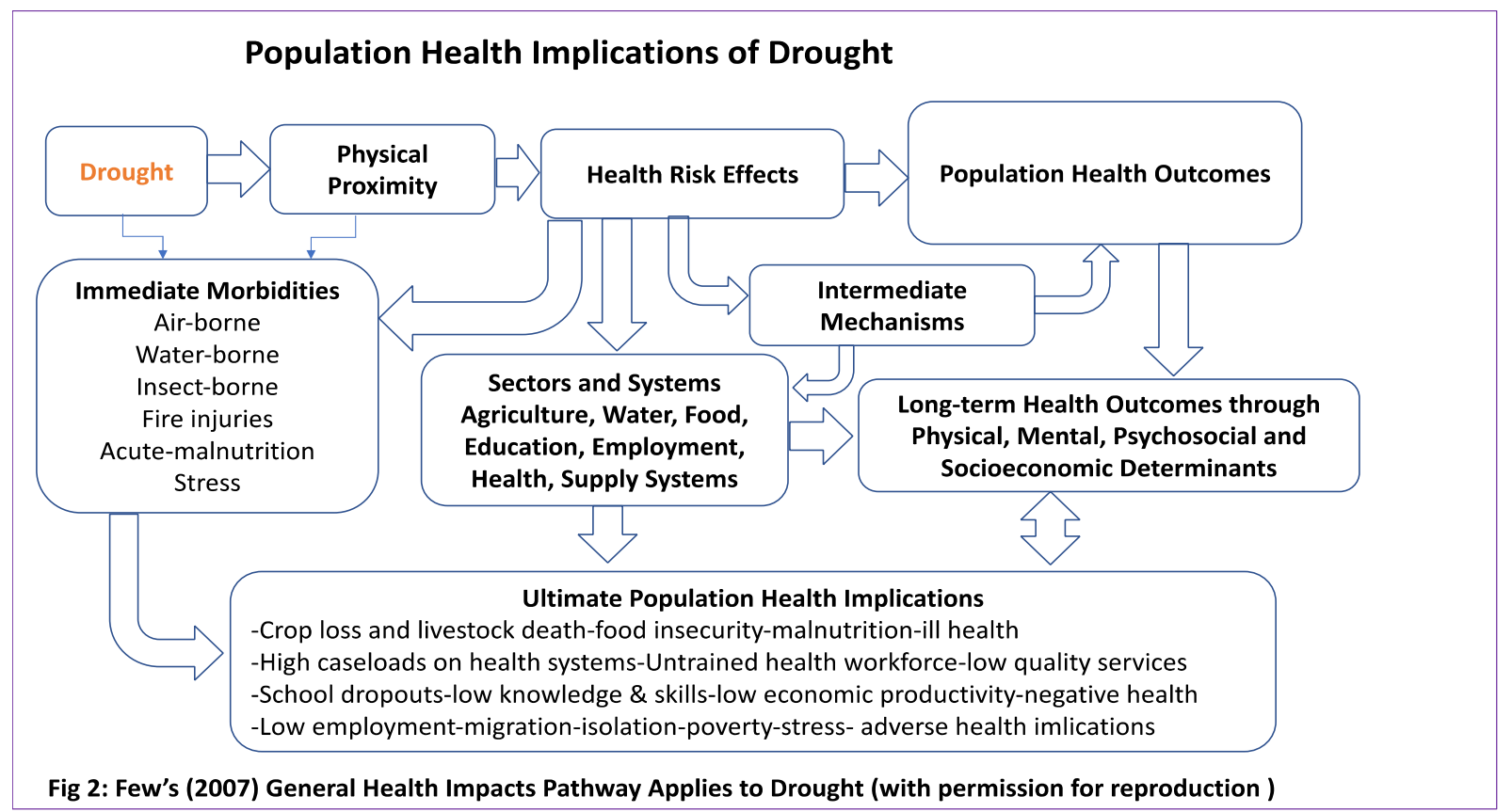

Figure 2. Few's General Health Impact Pathway Applies to Drought

The immediate health effects derive from direct heat, ultraviolet radiation, dust, and airborne pollution (Hendrix, 2012). Contaminated water enhances the risk of exposure to pathogens and other biological hazards. Drought-induced food insecurity ensues with acute malnutrition that has tripled since early 2015 (JGHP, 2017). In the long-term, this leads to low immunity, increased infection rates, and ill health (Wright \& Vesala-Husemann, 2006). Malnourished children grow up with life-long health implications like cognitive impairment and hinder development (World Bank, 2015). The shortage of water compromises sanitation and hygienic practices that relate not only to water-borne diseases but also to other food-borne, insect-borne, helminthic, and zoonotic ailments (Hendrix, 2012).

The indirect health effects manifest through intermediary mechanisms like scarce water resources, crop failure, and loss of livestock (Taye et al., 2010). Drought disrupts supply systems, despite increased demand for essential 
commodities. This results in food price inflation. To stay afloat, people sell their animals at a negligible cost. This liquidation of assets and borrowing of money pushes some households down to the social gradient (McCann, 1987).

With a sharp reduction of agricultural outputs and related employment, young people from land-poor households migrate to search for work and food (Birhanu et al., 2017). People move to the internally displaced population camps or cross borders; where again, precarious living conditions and isolation from the family adds to their stress (Gray \& Mueller, 2012). Thus, drought-induced mobilization underlies both physical and psychosocial ill health (Berry et al., 2010).

The drought has a cascading effect on education, particularly on girls who cannot attend school because they must collect water. Thus, drought has a lasting impact on education, employment, and income, which in turn, impact socioeconomic progress. It also changes demographic behaviours of farming communities; people are more likely to get married early, have many children, and experience child abuse, and sexual and gender-based violence (Ezra, 2001). These all affect population health outcomes and hold national progress back.

\subsection{Drought Vulnerability (Note 1) from 'Eco-social' Perspective}

Ethiopia has experienced several conflicts with neighboring countries and protracted civil wars within the state where repressive governments struggled for power exploiting famine as a tool of war against the oppositions (UCDP, 2016). The civil unrest was aggravated once again in 2016, and the government declared a six-month state of emergency (Human Rights Watch, 2016). This further limited people's movement; thus, restricted the ways to look for alternative livelihoods. The worst stunting (Note 1) rate in Africa, recorded among the Ethiopian children was $40 \%$ in 2014 indicating chronic malnutrition, explains these long-drawn-out socio-political crises (CSA, 2014). The problem is unimaginably worse in the conflict-afflicted agro-pastoralist communities (Delbiso et al., 2016). Although the toll on human lives determines the severity of a disaster, population health impacts are far-reaching and beyond such estimations. While enhanced preparedness using modern technology recently decreased the number of deaths from disasters, several factors have enhanced the health-damaging effects of drought in the marginalized agro-pastoralists compared to others in Africa (Nomura et al., 2016). These include the geographical location that is under direct El Niño effect of Indian Ocean, intensified degradation of the environment, and increased demand of a growing population on the limited natural resources. Among others are the protracted civil conflicts, discriminative and repressive past policies in the areas like land ownership, inter-state borders, forced resettlement, and unplanned urbanization (Nomura et al., 2016; Downie, 2016; Delbiso et al., 2016).

Acknowledging both the natural and man-made influences on the drought-related outcomes of population health, the Ecosocial model (Krieger, 2001) is merged with Few's (2007) general health impact pathway to portray the trajectories to drought and their impacts on the determinants of population health. The multilevel ecosocial theory "seeks to integrate social and biologic reasoning, along with the dynamic, historical, and ecological perspectives to address population distributions of disease and social inequalities in health" (Krieger, 2001, p.674). Studies determine that a context-specific rather than a broader global framework is more efficacious to guide resilience building through making the best out of local knowledge, resources, and capacities (Liao, 2014). We incorporate the constructs (in red) from such a locally developed resilience model (Tadesse, 2016) into the framework (Figure 3 ). These illustrate the complex causal pathways to drought and population health outcomes. 


\section{Pathways to Drought and Determinants of Population Health}

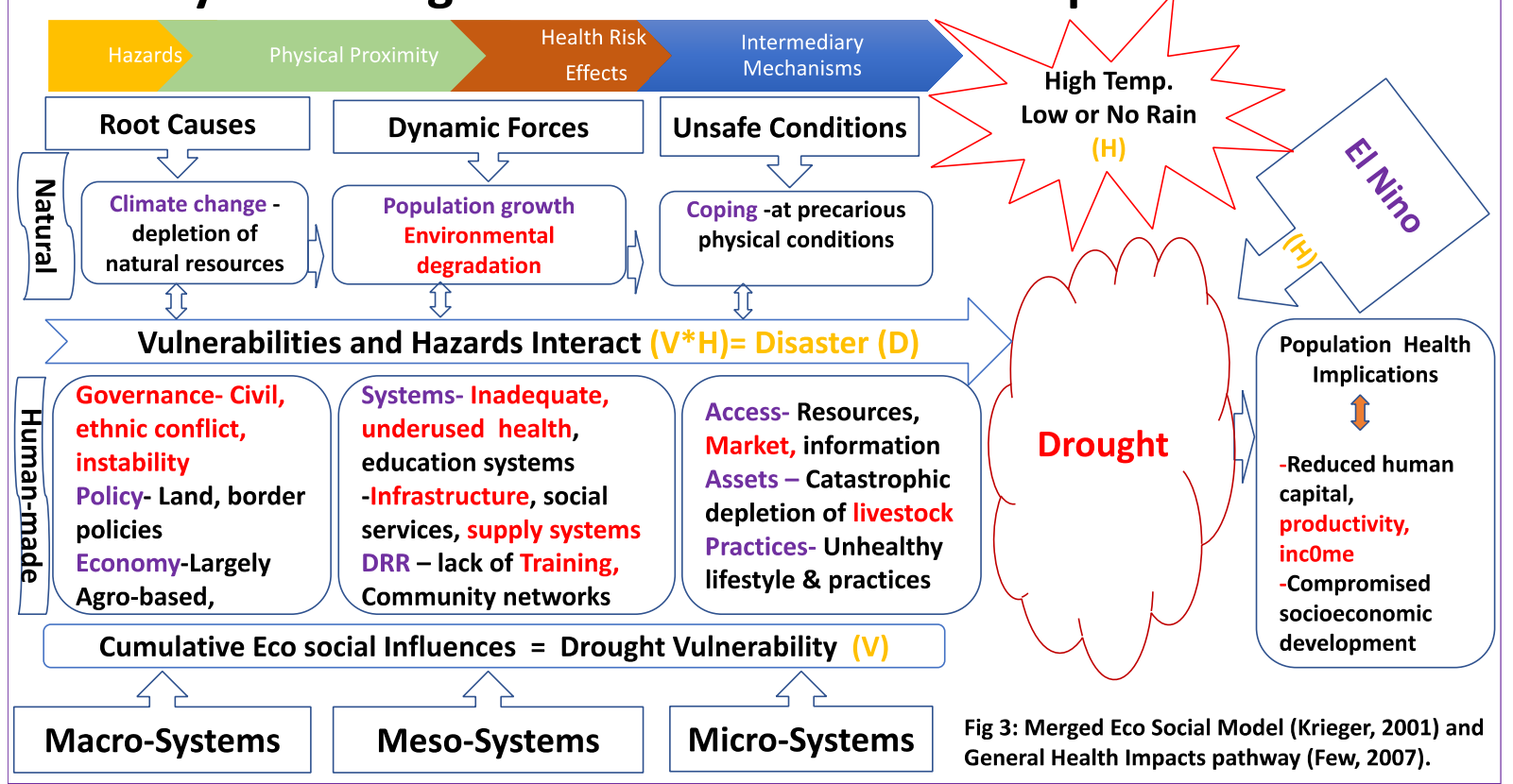

Figure 3. Eco social framework showing the pathways to drought and determinants of population health (Krieger, 2001)

\subsection{Complex Causal Pathways to Population Health Outcomes}

The causal pathway starts with the hazard that exerts health risk effects directly on the physical proximity. In the arid and semi-arid agro-pastoralist communities, health issues do not manifest out of a vacuum rather they are predisposed by the natural and human-made contextual determinants marked as the root causes (Birhanu, 2017). The macro-level land policy takes away the tenure security of the estate people own, so they cannot start any long-term farming project on the land they reside (Ambaye, 2012). Similarly, the inter-state border policy restricts their movements with herds for pasture (Ambaye, 2012). They have no access to the market (Leta \& Mesele, 2014). The whole pathway is again lodged within the more significant global geopolitical contexts having impacts from globalization and urbanization (Leta \& Mesele, 2014).

The intermediary mechanisms stem from the mesosystem influencing the health outcomes through organizational structures, services, and actors that provide health care, training, survival skills, and equipment. The systems' processes and practices are relevant as they could put optimal rules and regulations, effective early warning and surveillance systems with information exchange and coordination mechanisms in place. In the absence of these, there are no social services and securities; resources are used unsustainably; thus, the health systems remain ineffective (Hendrix, 2012). At the top of it, dynamic forces like the processes of climate change are making limited environmental resources insufficient for the rapidly growing population (GWPEA, 2015; Liao, 2014).

Health outcomes are also related to the microsystem determinants like the material resources of individuals and families (Krieger, 2001). One of the key informants from the studythat developed resilience model describes how profoundly the community depends on livestock:

"People use cattle as their food and cloth, to send their children to school and as their means of generating household income. The drought has impoverished most of the households and degraded their capacity, worsening their vulnerability" (Birhanu, 2017, p.6). Individual biological factors determine physical ability and are essential for those who should earn a wage by physical work for their dependents (Hendrix, 2012). Vulnerabilities are again subject to the household resources that help survival during adversity (Liao, 2014). The level of education, training, and skills that build human capital determine health behaviors (Birhanu, 2017). These in turn shape attitudes, mental ability to endure stress and to avert suicidal tendency (Birhanu, 2017). These all factors have implications for the health of family members and wellbeing of the community, in general (Honore, 2008). Thus, the framework above illustrates how the complex macro, meso, and microsystems determinants exert a cumulative eco-social influence, interact with the natural, environmental, and human-made factors, thereby, constitute the vulnerability of the affected population. The hazard, like drought here, interacts with this vulnerability status to create a 
disastrous situation that underpins the population health implications (Figures 2, 3). These health implications are disproportionately distibuted among certain vulnerable sub-population such as women, girls, elders, people with some disabilities and chronic diseases, people of lower socioeconomic groups who have been marginalized for having low or no political voice. Such an intersectionality analysis should guide the health program planning that aims to build resilience by addressing health inequality within the population sub-groups.

As mentioned before, the resilience constructs merged with the ecosocial frameworks (Fig 3) were developed with a methodologically rigorous qualitative study taking the grounded theory approach with the field level works in the agro-pastoralist communities (Birhanu, 2017). That scientific data-driven model featured eight closely linked dimensions that operate at multiple action levels. The primary dimension is the environment, associated with the underlying causes of vulnerability. The three others relate to the immediate cause and effects, are wealth, livestock, and infrastructures with social services. Other two relate to resilience, are the supporting community networks (social capital) and good governance (peace and security). The rest two are outcome-oriented such as psychosocial distress and human capital. The framework illustrates the relationships among these dimensions in the context of recurrent droughts and indicates the leverage points for actions (Birhanu, 2017). Fitting these dimensions into the above WHO's framework helped to identify intervention focuses (Fig 4). Research has identified how drought is having widespread impacts on many sectors of the society like agriculture, energy, food, water resources, tourism, and other industries depending on the natural resources and agricultural products (Tadesse et al., 2016). The associated impacts on the health of population vary according to their socio-economic positions. As shown in the causal pathway, the mechanism of impacts intertwines with the political, social, and economic policies and practices. These again provide structure how different service systems are organized and delivered. The mere presence of persuasive policies and strategies are not enough by themselves rather their uniform implementation across the regions and covering all the population; especially the vulnerable subpopulation is crucial to building health resilience. Otherwise, whenever a disaster hits, the gravity of impact falls disproportionately upon the vulnerable subpopulation.

The color and size of the arrows indicate the urgency (highlighted in red) and effects (indicated in the breadths and lengths of the arrows) of actions. While putting the vulnerability factors in the WHO's (2010) Commission on the Social Determinants of Health (CSDH) conceptual framework for action, (Figure 4) the pathway to the inequality in health becomes clear. This indicates the trajectories to the vulnerability and leverage points for action at different levels to address health inequality; thus, ensure health resilience (UN, 2016).

\section{Health Inequity: Leverage Points for Action}

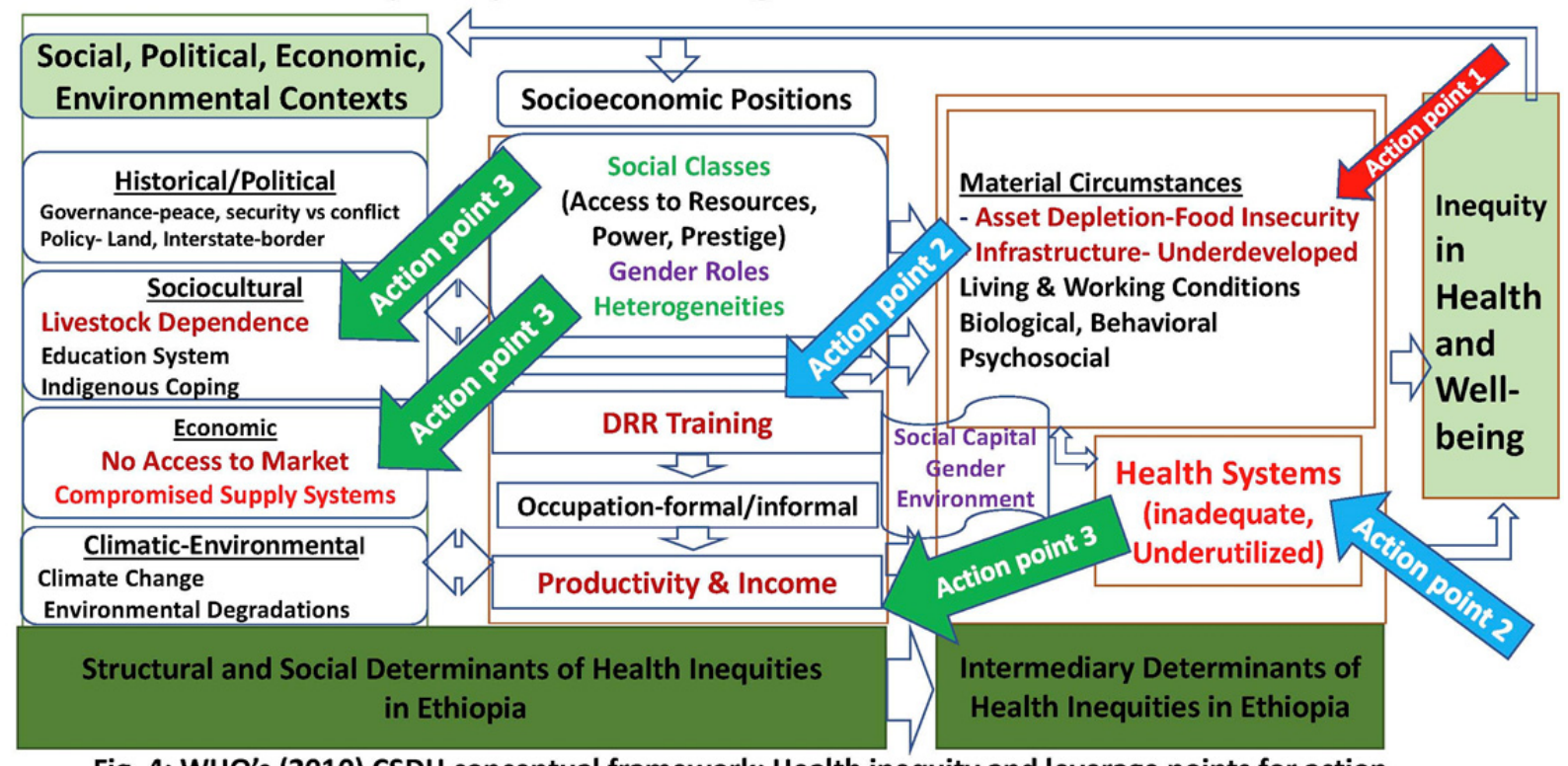

Fig. 4: WHO's (2010) CSDH conceptual framework: Health inequity and leverage points for action

Figure 4. WHO's CSDH Conceptual Framework: Health Inequity and Leverage Points for Actions 


\subsection{Ethiopian Potential}

Sendai Framework guides us to build on local resources and capacities. Thus, before deciding on such interventions, there is a need to explore the potential of existing interventions that are running in that context. During 2000-2011, Ethiopia showed progress in the key economic and development indicators (Geiger et al., 2013). During this decade, average GDP grew by over $10 \%$ annually, and the population living below the national poverty line declined from $44 \%$ in 2000 to $30 \%$ in 2011 (FAO, 2016). In 2014, Ethiopia was on track to achieve six of the eight millennium development goals, and in 2015, the country reached the MDG target of reducing extreme hunger by half (UN, 2015). Before these achievements, the GoE launched the Productive Safety Net Program (PSNP) in collaboration with the World Bank in 2005 and adopted a national nutrition strategy in 2007 (World Bank, 2015). Since then, many programs have been running with the aim to improve nutrition health and practices that explain the declining trend. A recent meta-analysis synthesizing available data shows the efficacy of PSNP in the severely drought-affected areas (Delbiso et al., 2017). Both the beneficiaries and communities tag PSNP as a useful program regarding the development of community infrastructure besides ensuring food security (UN, 2015). However, there is a lack of capacities and resources to scale out the program in all drought-affected areas. The situation warrants employing a collaborative interdisciplinary population health approach that can patrol the relief efforts towards sustainable development. One such service learning and capacity building program was previously piloted and proved effective in building capacities in out-reach areas. A competent workforce can be developed cost-effectively by the institutionalization of the mandatory field level service learning programs at all Ethiopian universities (Downes, Murray, \& Brownsberger, 2007; Lautze et al., 2003).

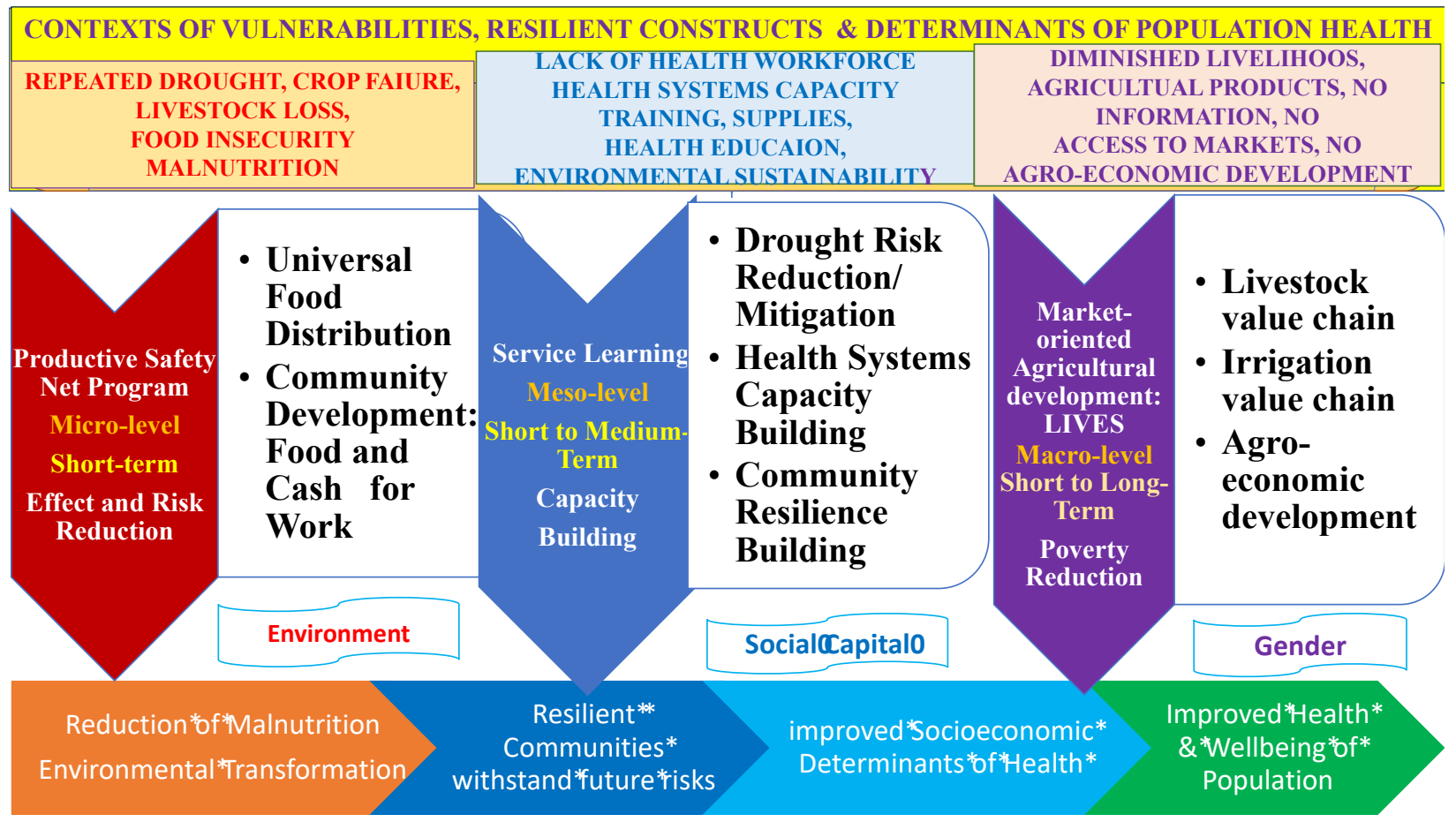

Figure 5. Proposed intersectoral interventions: Author’s framework with ideas from WHO (2010)

The proposed three interventions: a) Productive Safety Net Program (PSNP), b) Service Learning Capacity Building Program (SLCB), and c) Livestock and Irrigation Value Chains for Ethiopian Smallholders (LIVES) (ILRI \& IWMI, 2013). These interventions were successfully implemented either in the past or are running currently in different forms and areas benefiting the target communities. These interventions can be improved building upon the existing infrastructure and resources. These PHIs have the potentials to secure national, regional and local community buy-in; thus, feasible to start within the given timeline. Fig 5 above illustrates how the interventions are based on the contexts of vulnerabilities, resilient constructs along with their components and expected outcomes. Below is a short outline of the criteria based on what the interventions are selected:

Criteria for the Selection of Population Health Interventions. Appreciating the intricacy of the pathways that lead to the population health outcomes and the multiplicities of underlying contextual factors, a complex adaptive 
systems' thinking is warranted to theorize the change processes within the proposed interventions to make them the best performing (Hawe, 2015). Accordingly, the proposed interventions are selected and designed have the following criteria: a) Evidence-based: All have proven effectiveness and demonstrated utilities. b) Coherent with the international, national, and regional policies and strategic priorities. c) Intersectoral: Involving multiple levels of governments, collaborating across sectors, and disciplines. d) Multilevel Approach: Addressing at the all three (micro, meso and macro) levels, different interaction points, and adopting different approaches, e) Feasible and Cost-effective: As built upon the existing program infrastructures, resources, and frameworks; focuses on prevention, voluntary efforts, and institutionalization of programs. f) Building Capacity of the local national workforces and communities. g) Comprehensive: Covering multiple facets of disaster preparedness (response, restore, mitigation, recovery, adaptation, rehabilitation and beyond). h) Interconnected to each other through feedback loops; thus, having synergies and applying i) Systems' Approach: Focusing on the interactive nature and interdependence of contextual factors to address the identified issues. j) Building Resilience of the communities so that the victims can endure future shocks. k) Creating potential mechanisms for Authentic Community Engagement and Providing Ownership of the programs to the national, regional and local community stakeholders and direct beneficiaries. 1) Potential to be Sustainable through capacity building, systems development, and institutionalization of the interventions. m) Equity-focused, as designed with an intersectionality analysis. n) Addressing Cross-Cutting Issues: Gender, Environment, and social capital as the most relevant issues. o) Empowering Women, revitalizing social networks, thus, enhancing p) Social Cohesion and q) Transforming the Environment with added developmental activities. r) Maximizing Positive Societal, Organizational, and Population-Level Health Impacts. Thus t) Demonstrating Accountability for the health outcomes (WHO, 2010) with a proposed joint evaluation plan Details of the three identified interventions are beyond the scope of this article but will follow in a second piece of article.

\section{Discussion}

The complex population health determinants identified with this systematic review are difficult to address with any single intervention. As Roger Few (2007) observed that the complex mechanisms that link hazardous events to health outcomes have dual effects both on the health of human and health systems. The health system in Ethiopia is highly decentralized with a health post at every Kebele (municipality) where two paid community health extension workers are deployed (CSA, 2014). However, the health system is miserably underutilized due to distance, cost, and quality. Frontline workers placed in drought-prone areas often lack basic training and left without adequate supplies. Besides, they have very negligible disaster preparedness training to be able to tackle the caseloads from such a widespread drought. Ironically, drought causes an increased need for health services but compromises the capacity of the health system to deliver that. Reasonably, the resilient framework mentioned above highlighted the importance of physical infrastructure and social services (Birhanu, 2017). These are among the prime determinants indicated in the WHO's CSDH framework to be addressed to ensure health resilience.

We noted that successive droughts deteriorated the capacities of pastoralist communities to cope up with the shocks. The communities are trying to adopt strategies like alternate labor participation and seasonal migrations as described before (Liao, 2014). They have, however, some other indigenous coping mechanisms (Gada (Note 2), Busa Gonofa (Note 3), Busa-konki (Note 4), Dabare (Note 5)) to support each other with whatever they have (Birhanu, 2017). Supporting the mechanisms that boost social capital and help to minimize drought shocks. As the drivers of these shocks are predominantly local, the local perspectives must be kept in mind while intervening to build health resilience (UN, 2016).

There is contested information that previously millions of dollars earmarked for the victims of famine went to buy weapons (BBC, 2010). Despite abundant developmental aids and existence of impressive policies, agro-pastoralist communities remained trapped in the most wretched poverty (Delbiso et al., 2017; UCDP, 2016). Thus, there is the need to find a balance when at one hand, Ethiopian parliament openly expresses reluctance to foreign aids that may undermine their national pride and discourage the vital tourism industry, and on the contrary, the GoE is now appealing for disaster relief (UNOCHA, 2017). Likewise, some Ethiopian farmers are reluctant to plant genetically modified foreign grains and consider cash grant as a disgrace (Birhanu, 2017). Evidence shows that the top-down disaster crisis management approach further marginalizes remote communities and increases dependency on external supports that severely affects local capacity building and sustainability (Hammond et al., 2002). Therefore, the table below presents some political, social, cultural as well as strategic administrative issues that are critical to consider before deciding how best to support the relief efforts focused on building health resilience (DRMERA, 2016; Geiger et al., 2013; UN, 2016). 
Table 1. Political, Social, Cultural, Administrative Considerations

Political, Social, Cultural and Administrative Issues Worth of Consideration

a. Maintenance of peace, stability, and security are crucial not only for the implementation of any population-level programs but also key to the development initiatives.

b. The agro-pastoralist communities are traditionally and culturally deeply attached to livestock, and there exists a social support system closely related to it; so, any project that focuses on livestock and social support systems will have great potential for success.

c. Assurance of strict compliance with the internationally agreed financial transparency,

accountability, and good governance should be the prerequisite before granting any allocation.

d. A central coordination cell should maintain collaboration with all the local, regional, national and international partners- the information e mechanism should be consolidated.

e. Early warning and comprehensive assessment should fully inform drought responses.

f. Drought management should be decentralized and nationalized to be handled by Ethiopians.

g. Along with smooth recovery and rehabilitation, the local, national capacity building should be the priority rather than delivering only disaster relief assistance during the crisis.

h. Health and health systems resilience building should be the priority to ensure the durable solutions.

i. A competent workforce can be developed in a cost-effective manner by the institutionalization of the mandatory field level service-learning programs at all Ethiopian universities.

j. Disaster preparedness and risk management should be integrated into all sectoral plans.

k. Adoption of a population health approach and addressing the structural and socioeconomic

determinants of health are critical to mitigate the issues linked to protracted vulnerabilities and health inequalities among the population sub-groups

These considerations will shape the ways resources are allocated, and importance is given to the health needs of the most vulnerable people living in the remotest corners of the country. Multilevel intersectoral actions are required to facilitate a holistic, integrated and sustainable response and recovery aiming to reduce health risk and vulnerability, building capacity and resilience of the health workforce and communities in a population health approach. Again, the details of the identified programs and intervention modalities are beyond the scope of this article that will continue in a second piece.

\subsection{Limitations}

The study is limited by number peer-reviewed articles and studies conducted on the ground in the agro-pastoralist communities in Ethiopia. Therefore, evidence from grey literature and administrative database are mostly used.

\section{Conclusion}

This framework review identified the population health outcomes, determinants underlying drought vulnerability and resilient dimensions and came up with the policies and strategies that proved effective and have the potential to contribute to assure health resilience and sustainable health systems development by addressing the determinants of health in a collaborative interdisciplinary approach. This unique focus is in accord with the Sendai Framework's proactive disaster response and health systems development goals as well as with the population health goals set by the WHO's Commission on Social Determinants of Health. As with the changing climate, droughts are becoming widespread in other parts of Africa (IPCC, 2014), evidence identified and lessons learned from the worst drought niche in Ethiopia can be useful to design proactive plans in tackling similar droughts in other parts of the continent. Future research carried out on the ground in agro-pastoralist communities would generate robust evidence useful to address the determinants to ensure health resilience for the vulnerable population.

\section{Acknowledgments}

We are thankful to the Global Commission of Social Determinants of Health and WHO's Country Director and Ministry of Health in Ethiopia. We are also thankful to The World Health Organization, Dr. Nancy Krieger, and Dr. Rogers Few for granting permission to use their frameworks for this systematic review. 


\section{Funding}

There was no fundfor this systematic review except library access support from the University of Ottawa's Merriest library.

\section{Competing Interests Statement}

All authors declare no conflict of interest.

\section{References}

Ambaye, D. W. (2012). Land rights in Ethiopia: Ownership, equity, and liberty in land use rights. Addis Fortune, 11(539), 1-27. Retrieved from http://tinyurl.com/n2n86d4

BBC News. (July3, 2010). Ethiopia aid 'spent on weapons. Retrieved August 5, 2017 from http://news.bbc.co.uk/2/hi/africa/8535189.stm

Berry, H. L., Bowen, K., Kjellstrom, T. (2010). Climate change and mental health: A causal pathways framework. International Journal of Public Health, 55(2), 123-32. https://doi.org/10.1007/s00038-009-0112-0

Birhanu, Z., Ambelu, A., Berhanu, N., Tesfaye, A., \& Woldemichael, K. (2017). Understanding resiliencedimensions and adaptive strategies to the impact of recurrent droughts in Borana Zone, Oromia Region, Ethiopia: A grounded theory approach. International Journal of Environmental Research and Public Health, 14(2), 118. https://doi.org/10.3390/ijerph14020118

Central Statistical Agency. (2014). Mini Demographic and Health Survey. Addis Ababa: Ethiopia.

Cheng, A., Mayes, S., Dalle, G., Demissew, S., \& Massawe, F. (2017). Diversifying crops for food and nutrition security: A case of teff. Biological Reviews, 92(1), 188-98. https://doi.org/10.1111/brv.12225

Delbiso, T. D., Rodriguez-Llanes, J. M., Altare, C., Masquelier, B., \& GuhaSapir, D. (2016). Health at the borders: Bayesian multilevel analysis of women's malnutrition determinants in Ethiopia. Global Health Action, 9, 302-04. https://doi.org/10.3402/gha.v9.30204

Downes, E. A., Murray, J. P., \& Brownsberger, S. L. (2007). The use of service-learning in drought response by universities in Ethiopia. Nurs. Outlook, 55(5), 224-31. https://doi.org/10.1016/j.outlook.2007.01.011

Downie, R. (2016). Improving relief and development responses to climate variability: Emerging lessons from the 2015-2016 El Ni-o in Southern Africa. Washington, DC: CSIS.

Drought Risk Management and Enhancing Resilience in Africa. (2016). African Drought Conference 2016. Retrieved from http://tinyurl.com/lmbutjb

Ethiopian government portal: Economy. (2016). Retrieved from http://tinyurl.com/1362ked

Ezra, M. (2001). Demographic responses to environmental stress in the drought- and famine-prone areas of northern Ethiopia. International Journal of Population Geography, 7(4), 259-279. https://doi.org/10.1002/ijpg.226

Few, R. (2007). Health and climatic hazards: Framing social research on vulnerability, response and adaptation. Global Environmental Change, 17(2), 281-95. https://doi.org/10.1016/j.gloenvcha.2006.11.001

Food and Agriculture Organization of the United Nations (FAO), International Fund for Agricultural Development (IFAD), \& World Food Programme (WFP). (2015). The state of food insecurity in the world 2015. Meeting the international hunger targets: Taking stock of uneven progress. Rome, Italy: FAO. Retrieved from http://www.fao.org/3/a-i4646e.pdf

Food and Agriculture Organization of the United Nations (FAO) \& National Drought Mitigation Center (NDMC). (2008, May). A review of drought occurrence and monitoring and planning activities in the near east region. Retrieved from http://www.ais.unwater.org/ais/pluginfile.php/516/course/section/175/Drought\% 20Occurrence $\% 20$ and $\% 20$ Activities $\% 20$ in $\% 20$ the $\% 20$ Near $\% 20$ East.pdf

Geiger, M., \& Moller, L. C. (2013). Ethiopia economic update II: Laying the foundation for achieving middle income status. Washington: World Bank Group. Retrieved from http://tinyurl.com/ldltup4. 4 sép:

Global Water Partnership Eastern Africa. (2015). Assessment of drought resilience frameworks in the Horn of Africa. Integrated drought management program in the Horn of Africa. Retrieved from http://tinyurl.com/3xwmgrm 
Gray, C., \& Mueller, V. (2012). Drought and population mobility in rural Ethiopia. World Development, 40(1), 134-45. https://doi.org/10.1016/j.worlddev.2011.05.023

Hammond, L., \& Maxwell, D. (2002). The Ethiopian crisis of 1999-2000: Lessons learned, questions unanswered. Disasters, 26(3), 262-79. https://doi.org/10.1111/1467-7717.00204

Hawe, P. (2015). Lessons from complex interventions to improve health. Annual Review of Public Health, 36(1), 307-323. https://doi.org/10.1146/annurev-publhealth-031912-114421

Hendrix, M. (2012). Water in Ethiopia: Drought, disease and death. Global Environmental Change, 3(2), $110-120$.

Human Rights Watch. (2016). Such a brutal crackdown: Killing and arrests in response to Ethiopia's Oromo protests. Retrieved from http://tinyurl.com/keze652

Intergovernmental panel on climate change. (2014). Impacts, adaptation, and vulnerability. Part A: Global and sectoral aspects. Contribution of working group II to the fifth assessment report of the IPCC. Geneva, Switzerland: IPCC.

Joint government and humanitarian partners' document. (2017). Humanitarian requirements document. Retrieved from http://tinyurl.com/mpkxm3j

Kindig, D., \& Stoddart, G. (2003). What is population health? American Journal of Public Health, 93(3), $380-383$. https://doi.org/10.2105/AJPH.93.3.380

Krieger, N. (2001). Theories for social epidemiology in the 21st century: An ecosocial perspective. International Journal of Epidemiology, 30(4), 668- 677. https://doi.org/10.1093/ije/30.4.668

Leta, S., \& Mesele, F. (2014). Spatial analysis of cattle and shoat population in Ethiopia: growth trend, distribution and market access. Springer Plus, 3(1), 310. https://doi.org/10.1186/2193-1801-3-310

Liao, C. (2014). ACSF-Oxfam rural resilience project: Case study. Retrieved from PubMed with full text: https:/www.ncbi.nlm.nih.gov/pubmed/17279861

Lautze, S., Aklilu, Y., Raven-Roberts, A., Young, H., Kebede, G., \& Leaning, J. (2017). Risk and vulnerability in Ethiopia: Learning from the past, responding to the present, preparing for the future. US Agency for International Development; 2003 (cited 2017 May 28). Retrieved from http://www.who.int/hac/crises/eth/sitreps/risk_ethiopia.pdf

McCann, J. (1987). The social impact of drought in Ethiopia: Oxen, households, and some implications for rehabilitation (pp. 245-67). Cambridge, NY: Cambridge University Press.

Ministry of Agriculture of Ethiopia. (2013). Regional pastoral livelihoods resilience project: Resilience policy framework. Addis Ababa, Ethiopia: Ministry of Agriculture.

National Oceanic and Atmospheric Administration. (2012). Droughts fact sheet. Retrieved from http://www.nws.noaa.gov/om/csd/graphics/content/outreach/brochures/FactSheet_Drought.pdf

Nomura, S., Parsons, A. J., Hirabayashi, M., Kinoshita, R., Liao, Y., \& Hodgson, S. (2016). Social determinants of mid- to long-term disaster impacts on health: A systematic review. International Journal of Disaster Risk Reduction, 16, 53-67. https://doi.org/10.1016/j.ijdrr.2016.01.013

Tadesse, L., \& Ardalan, A. (2014). Health sector initiatives for disaster risk management in Ethiopia: A narrative review. PLoS Currents, 6, 1-52. https://doi.org/10.1371/currents.dis.949664319ad451313b499f9c90cd9c0f

Tadesse, T. (2016). Strategic Framework for drought management and enhancing resilience in Africa. Retrieved from http://tinyurl.com/lmbutjb

Taye, A., Haile-Mariam, D., \& Murray, V. (2010). Interim report: Review of evidence of the health impact of famine in Ethiopia. Perspectives in Public Health, 130(5), 222-6. https://doi.org/10.1177/1757913910379197

United Nations International Strategy for Disaster Reduction. (2009). Terminology on DRR. Retrieved from http://www.unisdr.org/ terminology

United Nations Office for the Coordination of Humanitarin Affais. (2017). Horn of Africa: A call for action. Retrieved from http://tinyurl.com/kn2fjze

United Nations. (2015). Millennium Development Goals report 2014: Ethiopia. Assessment of Ethiopia's progress towards the MDGs. Addis Ababa: National Planning Commission and the United Nations in Ethiopia. Retrieved from http://tinyurl.com/kaurrm7 
United Nations. (2016). Transforming our world: The 2030 agenda for sustainable development. Retrieved July 31, 2017, from http://tinyurl.com/z4o6pk4

Uppsala Conflict Data Program. (2016). Conflict encyclopedia. Uppsala: University of Uppsala. Retrieved from http://ucdp.uu.se/

World Bank. (2015). Ethiopia's productive safety net programme: Integrating disaster and climate risk management: Case study. Building resilience. Washington: World Bank Group. pp. 1-19. Retrieved from http://tinyurl.com/ltt9adw

World Health Organization. (2010). A conceptual framework for action on the social determinants of health: Debates, policy \& practice, case studies. Retrieved from http://apps.who.int/iris/bitstream/10665/44489/1/9789241500852_eng.pdf

Wright, M., \& Vesala-Husemann, M. (2006). Nutrition and disaster preparedness: Focusing on vulnerability, building capacities. Online Journal of Issues in Nursing. Retrieved July 31, 2017, from https://www.ncbi.nlm.nih.gov/pubmed/17279861

\section{Notes}

Note 1. Children are defined as stunted if their height-for-age is more than two standard deviations below the WHO Child Growth Standards median. (http://www.who.int/nutrition/healthygrowthproj_stunted_videos/en/)

Note 2. Gada is an indigenous conflict management and resolution practices to maintain peace (Birhanu, 2017)

Note 3. Busa Gonofa is restocking drought affected families (Birhanu, 2017)

Note 4. Busa-konki is to collect and redistribute milk to the poor households (Birhanu, 2017)

Note 5. Dabare is to provide milk cows to drought affected households on a temporary basis (Birhanu, 2017)

\section{Copyrights}

Copyright for this article is retained by the author(s), with first publication rights granted to the journal.

This is an open-access article distributed under the terms and conditions of the Creative Commons Attribution license (http://creativecommons.org/licenses/by/4.0/). 